\title{
Variability of Quality of Life at Small Scales: Addis Ababa, Kirkos Sub-City
}

\author{
Elsa Sereke Tesfazghi $\cdot$ J. A. Martinez $\cdot$ J. J. Verplanke
}

Accepted: 6 September 2009/Published online: 26 September 2009

(C) The Author(s) 2009. This article is published with open access at Springerlink.com

\begin{abstract}
Urban quality of life (QoL) is becoming a subject of urban research mainly for western and Asian countries. Such attention is due to an increasing awareness of the contribution of QoL studies in identifying intervention areas and in monitoring urban planning policies. However, most studies are carried out at city or country level that can average out details at small scales. In this paper we present a case study where the urban QoL at small scale is measured and its variability is evaluated for Kirkos sub-city of Addis Ababa, Ethiopia. The study is based on data from a household survey and some secondary data. Geographic information system (GIS) is applied to extract proximity information (e.g., distance to school facilities) and visualize the spatial distribution of QoL. Statistical methods such as factor analysis are applied to establish an index of objective QoL while coefficient of variation is applied to evaluate spatial variability of subjective QoL. The results of this study reveal that the subjective quality of life (QoL) scores show large variation in the sub-city. The mean QoL score also indicates that the respondents in the sub-city, on average, are dissatisfied with the quality of their life. Respondents with higher education level and income are on average, however, more satisfied with their QoL in the sub-city. The results reveal that the lower the QoL in the Kebele, the larger the variability of QoL within the Kebele. Such indicates how aggregation at large scale can average out the variation of QoL at small scales. The results reveal the presence of QoL variability at small scales. The comparison between the subjective and the objective QoL at Kebele level indicated a state of dissonance, adaptation, deprivation or well-being. Such results suggest that the two measures do not always indicate the same level of QoL.
\end{abstract}

Keywords Quality of life - Quality of life variability · GIS · Kirkos sub-city · Addis Ababa

E. S. Tesfazghi $(\bowtie)$

Helvetas Ethiopia, Addis Ababa, Ethiopia

e-mail: serelsa@yahoo.com; sereke18485@itc.nl

J. A. Martinez · J. J. Verplanke

Department Urban and Regional Planning and Geo-Information Management, International Institute for Geo-Information Science and Earth Observation-ITC, Enschede, The Netherlands 


\section{Introduction}

Quality of life (QoL) has been a subject of study in the field of several disciplines (Foo 2000; Bonaiuto et al. 2003; Li and Weng 2007; Møller 2007; Brereton et al. 2008; Lee 2008; Moro et al. 2008). The outcomes of urban quality of life studies may help city planners to understand and prioritize the problems that the community face. As stated by Lee (2008), QoL information can be used to diagnose previous policy strategies and to draft future planning policies. As a result, research in this field can lead to improvements in the QoL of residents.

Most of the quality of life studies cover cities of the western countries, see Rogerson et al. (1989) and Wong (2001) for England; Marans (2003) for Detroit metropolitan area in USA; Møller (2007), Higgs (2007) and Richards et al. (2007) for South Africa; Moro et al. (2008) for Ireland; Lee (2008) for Taiwan. However, quality of life studies for the cities in the East Africa region, particularly for Ethiopia, are noticeably absent. As such there is a need to evaluate and adapt the QoL concepts which were developed for the developed world and Asian countries to the East Africa region.

Commonly quality of life is studied at regional and country level. The purpose of studying QoL at those levels is mainly to compare its variations and in some cases benchmarking different areas. Such comparisons can also be complemented with better knowledge on local variability in quality of life. Studies that show the small scale variability of QoL are, however, rare although it is often the case that interventions are targeted and implemented at smallest administrative levels.

Quality of life is often measured using either subjective or objective indicators. Subjective indicators are derived from surveys of resident's perception, evaluation and satisfaction with urban living. Lee (2008) stated that quality must be subjective and the most appropriate method of exploring QoL is by directly asking people about their perception. Subjective QoL is often measured on a Likert scale usually ranging from 'very dissatisfied' to a 'very satisfied'. ${ }^{1}$ Bramston et al. (2002), Ibrahim and Chung (2003), McCrea et al. (2006) and Lee (2008) used subjective indicators to measure quality of life. Subjective methods are preferred over objective methods, particularly for planning and policy purpose, as it is able to provide more valuable feedback (Ibrahim and Chung 2003). Subjective indicators offer valuable information when tackling community based issues through a bottom up approach. However, as described by Foo (2000), subjective indicators have lower reliability and higher validity than objective indicators. One reason for the problem of reliability for subjective reporting, as also stated by Das (2008), is that these indicators cannot represent the actual environmental conditions in which people live. Also, resident's subjective perception of well-being is often affected by expectations.

Objective QoL is measured using objective indicators which are related to observable facts that are derived from secondary data, see Li and Weng (2007) and Apparicio et al. (2008). Examples of secondary data include population density, crime rate, educational level and household characteristics. However, as stated in Foo (2000), objective indicators themselves may not express the true quality of life since these indicators have high measurement reliability but low validity in assessing human wellbeing. A very important fact is that quality can not be determined by objective conditions only and it is important to take into account subjective well-being of individuals. Also Das (2008) stated that these

\footnotetext{
1 There is no commonly defined range for the Likert scale. For instance, Foo (2000) applied a 5-point Likert scale ranging from a 'very dissatisfied' to a 'very satisfied' while Brereton et al. (2008) applied a 7-point Likert scale.
} 
Table 1 Sates of quality of life

\begin{tabular}{lll}
\hline & Objective condition & \\
\cline { 2 - 3 } & Good & Bad \\
\hline $\begin{array}{l}\text { Subjective condition } \\
\text { Good }\end{array}$ & Well-being & $\begin{array}{l}\text { Adaptation } \\
\text { Bad }\end{array}$ \\
\hline
\end{tabular}

indicators are very often imperfect and may suffer from either under reporting or over reporting.

As stated by Turksever and Atalik (2001), measuring quality of life using both subjective and objective measures is necessary to provide an understanding of QoL. Measuring quality of life using both indicators can benefit from the strengths of each of the perspectives, i.e., to arrive at more reliable and valid information about QoL. Such approach is also advocated by Rogerson et al. (1989), Marans (2003), Van Kamp et al. (2003) and Li and Weng (2007).

The combination of both subjective and objective QoL measures allows the comparison of the possible variations between the two perspectives. Depending on the level of QoL that is measured by subjective and objective indicators, there will be well being, deprivation, adaptation, or dissonance. As stated by Zapf (1984) cited in Craglia et al. (2004), if an individuals subjective feeling and objective living conditions are good then we say there is well being. If both conditions are bad then there is deprivation. On the other hand, if the subjective condition is good and the objective condition is bad there is adaptation. However, if the subjective condition is bad and the objective condition is good then there is dissonance (Table 1).

In this study, quality of life is measured in the Kirkos sub-city, Addis Ababa, Ethiopia, using subjective and objective attributes of individuals' life. The spatial variability of QoL at Kebele level is also analyzed. Objective QoL index is developed using both household and spatial variables. The subjective and the objective QoL in the sub-city are also compared in terms of some states of QoL. The first section of this paper starts with a description of the study area. In the second section the methodology of the study is presented. The third section continues presenting the results and discussion, including the subjective QoL measurement, the QoL variability, the objective QoL measurement and the comparison of both the subjective and the objective QoL. The conclusion is presented in the latter sections of the paper.

\section{Study Area Description}

\subsection{Kirkos Sub-City}

Kirkos sub-city is one of the ten sub-cities of Addis Ababa, Ethiopia. As shown in Fig. 1, Kirkos sub-city is located at the centre of Addis Ababa. National sport and cultural facilities such as Addis Ababa stadium and Meskel square are located in the sub-city. The sub-city hosts international offices such as the office for Organization for African Union (OAU) and the United Nations Economic Commission for Africa (ECA). 


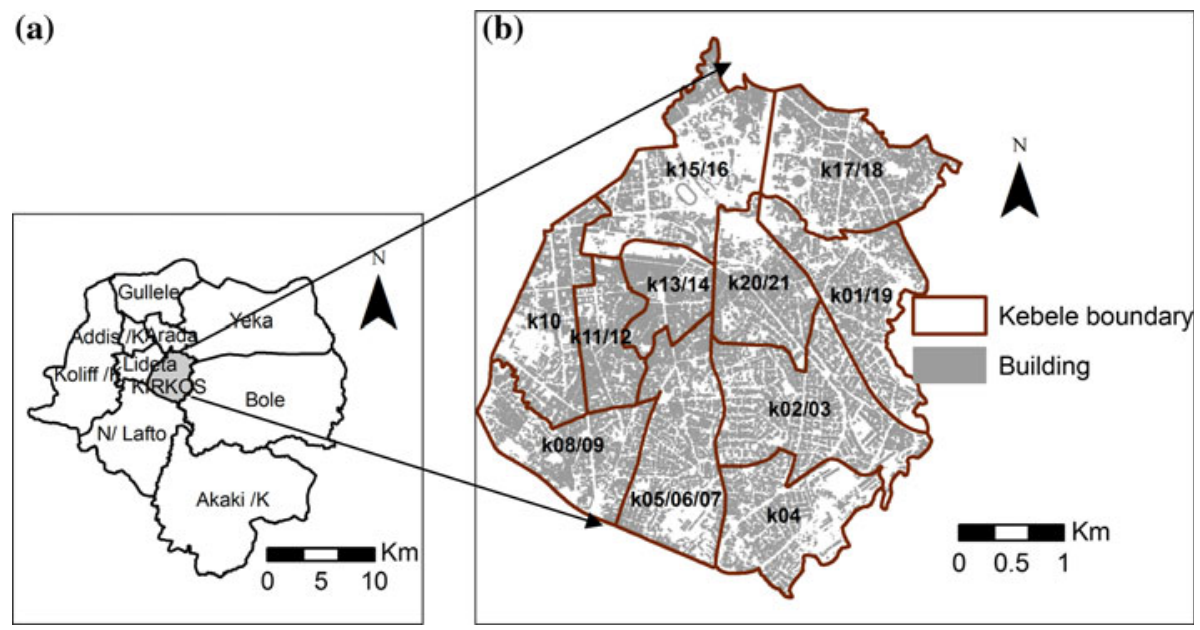

Fig. 1 Study area. a Addis Ababa sub-city boundaries, b building and road network in Kirkos

Kirkos sub-city covers a surface area of 1,472 ha and has a population size of about 220,991 (Central statistical agency of Ethiopia 2007). The sub-city is one of the densely populated sub-cities in Addis Ababa with a population density of 150 persons per hectare.

Kirkos sub-city is characterised by a combination of modern buildings and old residential settlements. Also as shown in Fig. 1 the sub-city is characterized by dense built-up areas. Superficial observations of Kirkos's residential areas suggest that it is inhabited by residents with high difference in income. The sub-city has 11 Kebeles, which constitute the smallest administrative levels in Ethiopia.

\section{Methodology}

\subsection{Data Set}

The data from 11 Kebeles of Kirkos sub-city, Addis Ababa was collected through interviews using a structured questionnaire during the period from 17 September 2008 to 17 October 2008. For the household survey, the main criterion was that the respondents must be head of the household. Moreover, the respondents must have lived in the sub-city for a minimum of 2 years.

A sample of 607 households is obtained through a stratified and systematic sampling method. A stratified sampling method is applied to classify the 11 Kebeles of Kirkos subcity into blocks or strata. First, Kebeles were classified into two to four large blocks mainly based on the old administrative boundary. Secondly, these large blocks or strata are classified into small strata based on residential structure which is mainly defined applying access roads as a boundary for the settlements. Prior knowledge of the study area as well as the use of Google earth and Quick Bird (2002) image was helpful in classifying areas for strata. The assumption is that residents that are grouped in same small stratum can share some common characteristics. The rational behind classifying the Kebeles into strata is to ensure spatial diversity of households from each block. Stratification is also applied to have 
representative sample of households and represent the heterogeneity in the sub-city as much as possible.

Systematic sampling method is used to identify the households during fieldwork. The total number of household in each Kebele is about 2,200-5,000. The interval for systematic sampling is calculated by dividing the total number of households by 55, which is the needed sample size from each Kebeles. Thus one household every 40-90 households were selected for interview.

The subjective quality of life $(\mathrm{QoL})$ in the sub-city is measured in terms of intuitive and rational response. During the household survey, both the intuitive and the rational quality of life were measured for two similar questions. The first question is: 'what do you feel about your life as a whole?' The response to this question is intuitive. The other question is 'Taking all the domains of life above into consideration, how satisfied are you with your life as a whole at present?' The response to this question is considered as rational. The rational response would be influenced by the answers to preceding questions and is therefore better thought through than the intuitive one, which is more instinctive. The domains of life selected in this study based on literature are housing, built-environment, neighbourhood safety, neighbourhood sanitation, quality of public services, access to public services, social connectedness and family income.

Data analysis was also performed to evaluate the objective quality of life in the sub-city. Prior to the analysis, data preparation on the 13 selected objective attributes (variables) was performed. The variables to measure objective QoL include both individual characteristics and spatial variables (Table 2). Some of the selected individual characteristics such as employment status, level of education and household tenure were categorical variables. These attributes are transformed into a score of $0-10$ based on their contribution to quality of life. This method of data transformation is adopted from Zebardast (2009). For instance, the variable employment status has two classes that are employed and unemployed. The categories are transformed into a minimum score of 0 and a maximum score of 10 . The assumption is that employed respondents have relatively high QoL than unemployed respondents. The variable Income is transformed using natural logarithm. The remaining household characteristics such as household size, number of dependent children and number of rooms in a house are continuous and no transformation is computed on these variables.

Geographic information system (GIS) is used to derive proximity variables which are nearest distance to school and health facilities. Following McCrea et al. (2005), the centroid of the block maps is used to identify the nearest distance to the facilities e.g., primary school.

Population density is measured as total population (2007) divided by total area of each Kebeles. Building density is measured as total built-up area divided by total surface area of each Kebeles. Crime rate is measured based on the description applied in Moro et al. (2008). ${ }^{2}$ It is measured as a number of reported crimes in each Kebeles per 100,000 of the population. Number of traffic accident is measured as number of reported accidents in each Kebele. The spatial variables are assumed the same for all respondents in the specific Kebeles.

\subsection{Subjective Quality of Life and its variability}

Descriptive statistics is applied to measure subjective quality of life at the sub-city level. The response is measured using a six point Likert scale that ranges from one for completely

\footnotetext{
${ }^{2}$ In Moro et al. 2008, crime rate is defined as the number of headline crimes in the respondent's local authority area per 100,000 of the population.
} 
Table 2 Objective variables description

\begin{tabular}{|c|c|c|c|}
\hline Variable name & Description & Type & $\begin{array}{l}\text { Transformed } \\
\text { score }\end{array}$ \\
\hline \multirow[t]{2}{*}{ Employment status } & Respondent is employed & Dummy & 10 \\
\hline & Respondent is unemployed & & 0 \\
\hline \multirow[t]{5}{*}{ Level of education } & Respondent is not educated & Dummy & 0 \\
\hline & Respondent has primary education & & 4 \\
\hline & Respondent has secondary education & & 7 \\
\hline & Respondent has vocational qualification & & 9 \\
\hline & Respondent has university degree & & 10 \\
\hline \multirow[t]{5}{*}{ Household tenure } & Respondent owns their home & Dummy & 10 \\
\hline & Respondent lives in Kebele house & & 7 \\
\hline & Respondent lives in private rented house & & 5 \\
\hline & $\begin{array}{l}\text { Respondent lives in housing agency rented } \\
\text { house }\end{array}$ & & 4 \\
\hline & Others & & 3 \\
\hline Income & Family monthly income (log) & Continuous & - \\
\hline Household size & Number of individuals in a house & Continuous & - \\
\hline $\begin{array}{l}\text { Number of dependent } \\
\text { children }\end{array}$ & Number of dependent children in a house & Continuous & - \\
\hline Number of rooms in a house & The total number of rooms in a house & Continuous & - \\
\hline Distance to school facilities & $\begin{array}{l}\text { Measured as the nearest distance to the schools } \\
\text { from the centroid of the block maps }\end{array}$ & Continuous & - \\
\hline Distance to health facilities & $\begin{array}{l}\text { Measured as the nearest distance to the health } \\
\text { facilities from the centroid of the block maps }\end{array}$ & Continuous & - \\
\hline Population density & $\begin{array}{l}\text { Measured as total population (of the year 2007) } \\
\text { divided by total area of each Kebeles }\end{array}$ & Continuous & - \\
\hline Building density & $\begin{array}{l}\text { Measured as total built-up area divided by total } \\
\text { surface area of each Kebeles }\end{array}$ & Continuous & - \\
\hline Crime rate & $\begin{array}{l}\text { It is measured as number of reported crimes in } \\
\text { each Kebele per } 100,000 \text { of the population }\end{array}$ & Continuous & - \\
\hline Number of traffic accident & $\begin{array}{l}\text { Measured as number of reported accidents in } \\
\text { each Kebele }\end{array}$ & Continuous & - \\
\hline
\end{tabular}

dissatisfied to six for completely satisfied. The cumulative percentage of respondents is calculated to compare the rational and intuitive QoL. Descriptive statistics is also applied to measure the QoL at Kebele level. The mean score is used to aggregate the QoL for each Kebele. GIS is used to visualize the distribution of QoL in the sub-city by creating thematic maps.

Following Turksever and Atalik (2001), spatial statistics in terms of the coefficient of variation $(\mathrm{CV})$ is applied to study the variability of the subjective QoL at Kebele level. ${ }^{3}$ GIS is applied to visualize the variability and to identify clustering of Kebeles with high or low variability by mapping the calculated CV for each Kebele.

\footnotetext{
3 The CV is computed as standard deviation of the QoL scores divided by the mean of the scores and it indicates an absolute variability. To evaluate the relation between QoL scores and its spatial variability, the correlation coefficient is computed between mean QoL and the CV.
} 


\subsection{Objective Quality of Life}

Factor analysis is applied to identify the underlying dimensions of objective quality of life in the sub-city. ${ }^{4}$

An index of objective quality of life is developed based on the method presented by $\mathrm{Li}$ and Weng (2007). The QoL index is established using the score of the dimensions of objective QoL that was estimated by the factor analysis. The overall score of each respondent is obtained by weighting each factor score by the respective variance. Following, Li and Weng (2007), in this study, the objective QoL index for Kirkos is developed by weighing the dimensions with the variance of the respective factors.

A minimum-maximum standardization technique is applied to transform the objective QoL score to score of 1-6 to have a similar range of values as that used for the subjective QoL. A score of 1 represents the lowest objective QoL and a score of 6 represents the highest objective QoL. The standardized score is aggregated using the mean value for each Kebele.

\subsection{States of Overall Quality of Life}

Following Das (2008), the correlation coefficient is applied to compare the scores of the subjective QoL and the index of the objective QoL derived for every individual households. The comparison between the subjective and the objective QoL at Kebele level is evaluated based on the theoretical concept that is described in Zapf (1984) cited in Craglia et al. (2004). First, the QoL score that is perceived by individuals is aggregated in terms of the mean score per Kebele. Next, the objective QoL score, which is established using factor analysis, is aggregated in terms of the mean score per Kebele. Finally, a two-way matrix is developed to assess the condition of both the subjective and the objective QoL for each Kebeles. GIS is used to visualize the four conditions of QoL in Kirkos sub-city.

\section{Results and Discussion}

\subsection{Subjective Quality of Life}

\subsubsection{Intuitive and Rational QoL Score at Sub-City Level}

Table 3 shows the percentage of respondents' in Kirkos sub-city that are categorized by level of subjective QoL based on their response. When respondents were asked about their intuitive QoL, 26\% expressed some level of satisfaction including 3\% who expressed

\footnotetext{
${ }^{4}$ Factor analysis is a statistical technique commonly used to extract a sub-set of uncorrelated dimensions that explain the variance observed in the original data set. With factor analysis it is possible to derive from a large set of variables a set of factors or dimensions. Each of them can be thought of as a macro or "super variable" that represents a cluster of highly correlated variables.

Priori to applying factor analysis, the suitability of the data was checked based on the Kaiser-MeyerOlkin (KMO) and Bartlett's tests. The requirement to apply factor analysis is that the KMO value must be great than 0.5 and the Bartleet's test value must be less than 0.1 ( $\mathrm{Li}$ and Weng 2007). To determine the number of factors extracted the eigenvalue criterion is applied.

In this study, orthogonal varimax rotation method is applied to ensure that the attributes are maximally correlated with only one factor and for ease of interpreting the factors. To ensure that the factor scores are uncorrelated and to avoid the influence of different measurement scale on the resulting score, the AndersonRubine method is carried in identifying the factor score coefficients.
} 
Table 3 Percentage of respondents with specific level of intuitive and rational QoL

\begin{tabular}{|c|c|c|c|c|}
\hline \multirow[t]{2}{*}{ Level of subjective QoL } & \multicolumn{2}{|l|}{ Intuitive QoL } & \multicolumn{2}{|l|}{ Rational QoL } \\
\hline & Percentage $(\%)$ & Cumulative (\%) & Percentage $(\%)$ & Cumulative (\%) \\
\hline Completely dissatisfied & 24 & 24 & 15 & 15 \\
\hline Very dissatisfied & 24 & 48 & 16 & 31 \\
\hline Dissatisfied & 26 & 74 & 31 & 62 \\
\hline Satisfied & 17 & 91 & 26 & 88 \\
\hline Very satisfied & 6 & 97 & 8 & 96 \\
\hline Completely satisfied & 3 & 100 & 4 & 100 \\
\hline Mean (Likert) & 2.67 & & 3.06 & \\
\hline Mode (Likert) & 3.00 & & 3.00 & \\
\hline Standard deviation $(-)$ & 1.3 & & 1.3 & \\
\hline
\end{tabular}

complete satisfaction. About $74 \%$ of the respondents said they are dissatisfied with their quality of life in general.

When respondents were asked about their rational QoL, 38\% expressed some level of satisfaction including $4 \%$ who expressed complete satisfaction. About $62 \%$ of the respondents said they are dissatisfied with their quality of life in general.

More respondents expressed dissatisfaction with life in terms of the intuitive response than the rational response (74 and 62\%, respectively). This implies that rationally the QoL is perceived better when respondents consider all the different domains of life. For both responses the (calculated) mode is three, i.e., most of the responses indicate 'dissatisfaction'.

The cause of the difference could be due to the reason that the intuitive response is instinctive and not well thought through. However, the rational response is well-thought through and influenced by the domain satisfactions. The result agrees with the finding by Ibrahim and Chung (2003) that reported higher percentages of respondents that are satisfied and very satisfied in terms of the rational response than the intuitive response for selected settlements in Singapore. Das (2008) reported a different result that a lower percentage of respondents were satisfied in terms of the rational response than the intuitive response for Guwahati, India. The above studies are carried out for Asian region and both studies applied a five point Likert scale. Although the studies suggest that there could be some difference between the two responses, the difference in study area makes comparison of the findings difficult.

For further analysis, wherever the subjective QoL was used in this study, it was preferred to consider the rational response. This was preferred since it showed high correlation with the domain satisfactions and since it is better thought through than the intuitive response.

\subsubsection{Rational QoL Score at Kebele Level}

Measuring QoL at the sub-city level is expected to hide variations in the QoL at a smaller scale, i.e., at Kebele level. The map in Fig. 2 shows the spatial distribution of the mean score of the rational QoL in Kirkos sub-city. Each polygon in the map defines a specific Kebele. Small values indicate Kebeles with low QoL while high values indicate Kebeles with high QoL. The map shows that rationally, the respondents' in the sub-city feel either satisfied (i.e., a value of 4) or 'dissatisfied' or worst (i.e., a value of less than 4) about their 


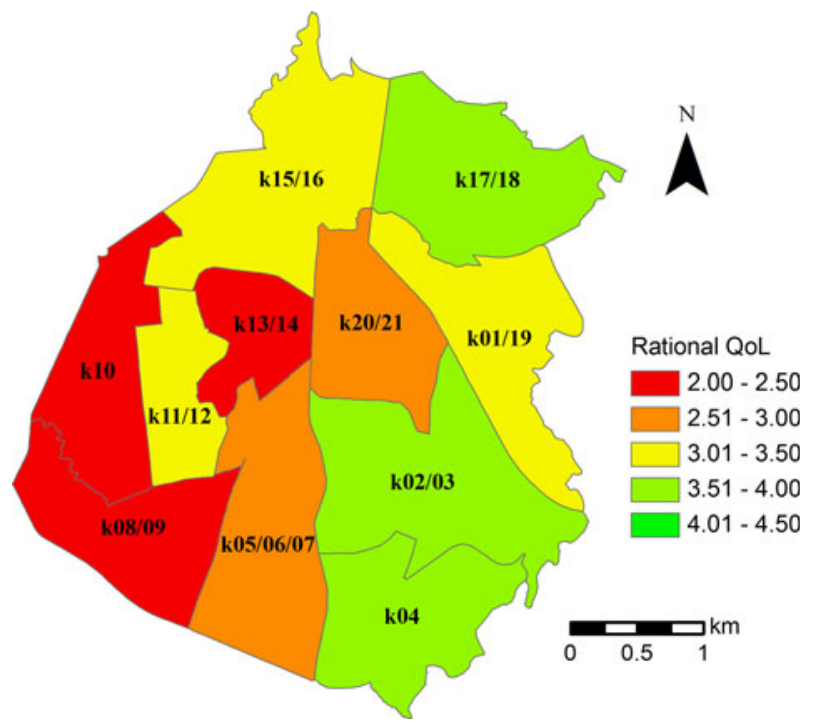

Fig. 2 Spatial distribution of averaged rational QoL in Kirkos sub-city. Note that a Likert scale of 1 represents 'completely dissatisfied', 2 represents 'very dissatisfied', 3 represents 'dissatisfied', 4 represents 'satisfied', 5 represents 'very satisfied' and 6 represents 'completely satisfied'

Fig. 3 Percentage of respondents' expressing any level of dissatisfaction in each Kebele

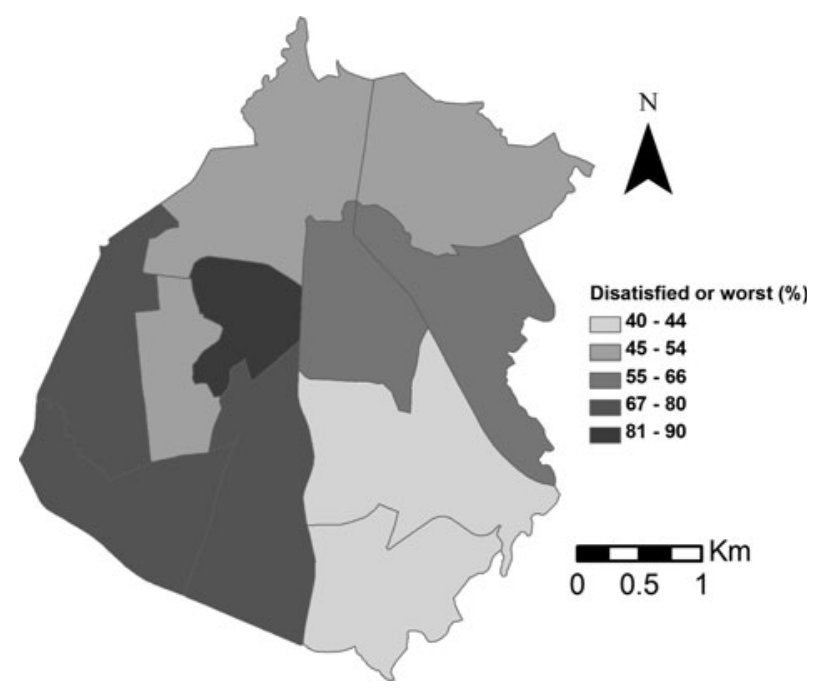

life. The map also shows that there is some pattern of clustering of Kebeles with high or low values. For instance, Kebeles with low QoL are clustered in the south-western part of the sub-city.

The map in Fig. 3 shows the percentage of respondents' expressing any level of dissatisfaction in each of the Kebeles. The highest percentage is shown in Kebele 13/14 and the lowest percentage is in Kebele 02/03. 


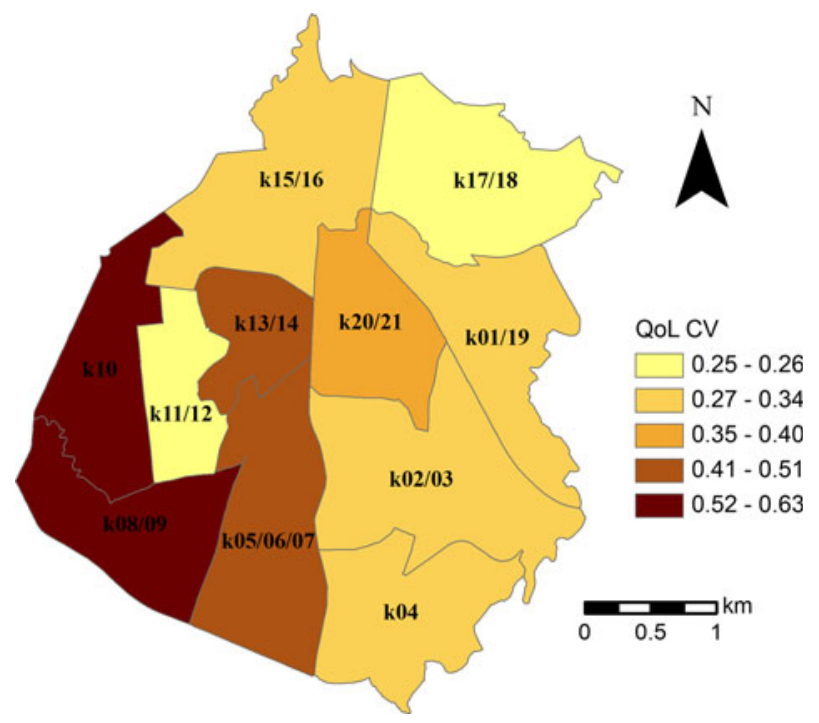

Fig. 4 QoL variability in terms of coefficient variation (CV). Note that high value indicates high variability

\subsubsection{Variability of Subjective Quality of Life at Kebele Level}

Although some heterogeneity in QoL is expected at small scales, studies that quantify such variability are rare in the literature. As such, one of the objectives of this study is to explore the variability of QoL within each Kebele of the Kirkos sub-city. This will help to evaluate if the Kebeles are heterogeneous or homogeneous in terms of the QoL of the residents. The outcome will indicate if studying QoL at lower level than the Kebele is necessary.

The variability of QoL at small scale, i.e., in a specific Kebele, is evaluated through coefficient of variation (CV). Figure 4 shows the $\mathrm{CV}$ of the mean rational QoL in each Kebele. The CV ranges from 0.25 to 0.63 . A small CV values imply less variability while high CV implies high variability. The map shows high QoL variability for Kebele 08/09 and Kebele 10.

After reviewing similar studies, the variability in the QoL at different scales that are country, city, district and census division levels are summarized in Table 4 which shows the CV at different level. The reviewed studies did not report the CV except Turksever and Atalik (2001). As such the CV of the remaining studies was calculated from the reported mean and standard deviations.

As shown in Table 4, the standard deviation in this study is much larger than that reported by other studies. However, standard deviation is affected by the mean score and as such the CV provides a much better explanation of the variability since it is the ratio of standard deviation and mean. The effect is that the measure of variability is not much dependent on the mean score. In terms of CV, QoL variability is mostly smaller at country level than at city, district or census division level. This shows how large scale studies average out the variability at small scale. The QoL of Kebeles with high variability can be further studied at sub-Kebele levels if there is a desire to prioritize intervention areas within a specific Kebele.

The relationship between mean subjective QoL and CV is shown in Fig. 5. Mean QoL scores correlates negatively with $\mathrm{CV}$ that suggests the higher the QoL the less variable the 
Table 4 Variability of subjective QoL at different scale

\begin{tabular}{lllllll}
\hline Literature & Description & Scale & $\begin{array}{l}\text { Standard } \\
\text { deviation }\end{array}$ & Mean & CV & Likert \\
\hline Foo (2000) & Singapore & Country & 0.63 & 3.55 & 0.18 & 5 \\
Turksever and Atalik (2001) & Istanbul & City & 0.50 & 1.48 & 0.34 & 4 \\
Das (2008) & Guwahati, India & City & 0.92 & 3.43 & 0.27 & 5 \\
Turksever and Atalik (2001) & Istanbul & District & & & $0.22-0.37$ & 4 \\
Foo (2000) & Singapore & Census division & & & $0.09-0.21$ & 5 \\
Tesfazghi (2009) & Addis Ababa & Kirkos sub-city & 1.30 & 3.06 & 0.43 & 6 \\
& & Kebele & & & $0.25-0.63$ & 6 \\
\hline
\end{tabular}

Fig. 5 Relation between coefficients of variation and mean QoL

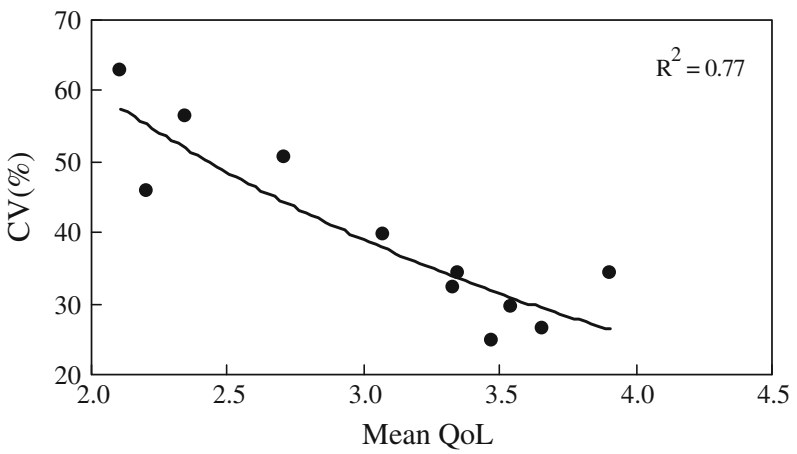

QoL is. This implies that those Kebeles with high level of QoL are relatively homogeneous in terms of QoL while Kebeles with low level of QoL are relatively heterogeneous in terms of QoL.

The exponential relationship between the mean subjective QoL and the $\mathrm{CV}$ value is defined in the following equation:

$$
\mathrm{CV}=143.96 \mathrm{e}^{-0.4349 M}
$$

where $\mathrm{CV}$ is coefficient of variation, $M$ is the mean score of the subjective QoL, and e is the base of natural logarithm which is 2.718 . The equation was fitted with $R^{2}=0.77$ that indicates satisfactorily performance.

\subsection{Objective Quality of Life}

\subsubsection{Factor Analysis}

There are several objective attributes (variables) that may affect quality of life. The main challenge is how to develop indices from these attributes that can be used to predict QoL. Factor analysis is applied in this study to develop these indices using several objective attributes. Thirteen variables which reflect both household and spatial characteristics are studied. 
Table 5 Factor loading matrix for objective QoL attributes

\begin{tabular}{|c|c|c|c|c|c|}
\hline \multirow[t]{2}{*}{ Attributes } & \multicolumn{5}{|l|}{ Factors } \\
\hline & 1 & 2 & 3 & 4 & 5 \\
\hline Building density & 0.918 & & & & \\
\hline Population density & 0.889 & & & & \\
\hline Employment status & & 0.823 & & & \\
\hline Education level & & 0.754 & & & \\
\hline Ln family Income & & 0.709 & & & \\
\hline Distant to health facility & & & -0.715 & & \\
\hline Number of traffic accident & & & 0.711 & & \\
\hline Crime rate & & & 0.625 & & \\
\hline Distance to school facilities & & & 0.609 & & \\
\hline Number of rooms in a house & & & & 0.828 & \\
\hline Household tenure & & & & 0.810 & \\
\hline Number of dependent children & & & & & 0.888 \\
\hline Household size & & & & & 0.869 \\
\hline Eigenvalue & 2.82 & 2.28 & 1.73 & 1.55 & 1.18 \\
\hline Percentage of variance explained & 19.57 & 14.35 & 13.91 & 13.60 & 12.15 \\
\hline$\%$ Total explained variance & $73.57 \%$ & & & & \\
\hline
\end{tabular}

Extraction method: principal component analysis

Rotation method: varimax with Kaiser normalization

The Kaiser-Meyer-Olkin (KMO) value is 0.59 and the Bartlett's significance test is 0.0 . This implies that the data is suitable for factor analysis. Five factors with an eigenvalue greater than 1 are extracted in this study.

The result of the factor analysis is shown in Table 5. Attributes with factor loadings of greater than 0.5 are considered in identifying the dimensions. A label or meaning is attached to each factor in the next section.

\subsubsection{Dimensions of Objective Quality of Life}

The factors that are shown in Table 5 can be considered as the underlying dimensions of objective QoL in the Kirkos sub-city. The five factors explain $73.57 \%$ of the total variance in the data set. The first factor explains $19.57 \%$ of the variance while the remaining factors explain $12.00-14.00 \%$ of the variance. This implies that the relative importance of the factors is almost equal and removing any one of the factors may result in loss of information.

The five factors are interpreted to define the dimensions of objective QoL in the Kirkos sub-city as follows:

First factor: This factor can be interpreted as crowdedness (CD) since it shows high loadings on building density and population density. The two variables are positively correlated with the factor. This suggests that the higher the score in this factor, the higher the crowdedness and the smaller the space for people to live

Second factor: This factor can be interpreted as socio-economic status (SE) since it shows high loadings for instance on employment status and family income. All the 
attributes are positively correlated with the factor. The higher the score in this factor, the higher the economic aspects of quality of life

Third factor: This factor is a combination of proximity and neighbourhood safety attributes. Crime rate, number of traffic accident and distance to school facilities are positively correlated with the factor, while distance to health facilities is negatively correlated with the factor. This may be a result of a statistical interaction between the safety and proximity variables. The factor can be labelled as a combination of safety and proximity dimension (SP)

Fourth factor: This factor can be interpreted as housing dimension (HD) of QoL since it shows high loadings on the number of rooms per house and household tenure. The two attributes are positively correlated with the factor indicating the higher the score of these attributes the higher the score of the HD of QoL

Fifth factor: This factor can be interpreted as demographic dimension (DM) of QoL. This factor shows high loading on number of dependent children and household size. The higher the score in this factor, the lower the number of people living in a house

\subsubsection{Objective QoL Index}

An index of quality of life is developed using objective attributes. This will help for designing future studies of urban QoL in the East Africa region. For instance, it can reveal the dominant dimension of QoL and as such the attributes of such dimension should be given more attention while designing data collection schemes. The QoL index is developed by combining the scores of the five selected factors that relate to the objective dimensions of QoL. The overall objective score of each respondent is obtained by weighting each factor score by the respective variance as follows.

$$
\begin{aligned}
\mathrm{QoL}_{i}= & \left(-19.58 \times \mathrm{CD}_{i}+14.35 \times \mathrm{SE}_{i}-13.91 \times \mathrm{SP}_{i}+13.60 \times \mathrm{HD}_{i}-12.15\right. \\
& \left.\times \mathrm{DM}_{i}\right) / 100
\end{aligned}
$$

where $\mathrm{QoL}_{i}$ is quality of life score of respondent $i, \mathrm{CD}_{i}$ is crowdedness score, $\mathrm{SE}_{i}$ is socioeconomic score, $\mathrm{SP}_{i}$ is safety and proximity score, $\mathrm{HD}_{i}$ is housing score and $\mathrm{DM}_{i}$ is demographic score of respondent $i$. The sign in the equation shows the direction of relationship between QoL and its dimensions. Socio-economic and housing dimensions have positive contribution to quality of life. This implies that the higher the score in the socioeconomic and housing dimension, the better the QoL. While crowdedness, safety-proximity and demographic dimensions have negative contribution to QoL in the sub-city. This implies that the higher the score in these dimensions, the lower is the QoL. For instance, the higher the score of crowdedness, the smaller the space for people to live and a consequent worse quality of life.

The objective QoL score that is estimated by applying Eq. 1 varies between -1.49 and 1.42. Minimum-maximum standardization method is applied to transform the score to 1-6 which is similar to the scale range of the subjective QoL score in this study. This will help for ease of comparability of the index with subjective QoL score in the sub-city. A score of 1 represents low quality of life and a score of 6 represents high QoL.

\subsection{Combined Subjective and Objective QoL}

The condition of QoL in each Kebele is identified as a state of deprivation, well-being, dissonance or adaptation based on the average score. A score of 3.5 is applied to 




Fig. 6 The combined effect of subjective and objective QoL in Kirkos sub-city

differentiate between 'good' and 'bad' QoL. If both the subjective and objective QoL are good then there is well-being while if both are bad then there is deprivation. If the objective is good but the subjective is bad then there is dissonance while if the objective is bad but the subjective is good then there is adaptation.

The map in Fig. 6 shows the distribution of the QoL depending on whether the subjective and the objective QoL in Kirkos sub-city are good or bad. Although the objective living condition in Kebele 11/12 is bad, the individual's perception of the living condition in that Kebele is good. In terms of QoL, we can say that there is adaptation in Kebele 11/12. The objective QoL in this Kebele is low mainly due to the fact that the Kebele is overcrowded and it has low level of housing conditions compared to other Kebeles. The subjective QoL of this Kebele is high compared to the objective QoL probably due to the fact that the respondents are satisfied with some of the domains of life. For instance, the respondents in this Kebele, expressed satisfaction with housing, built-environment, neighbourhood safety, access to public services and social connectedness.

On the other hand, despite good objective living conditions, the individually perceived subjective QoL in Kebeles 01/19, K10, K08/09 and K05/06/07 is bad or low. Therefore, we can say that there is dissonance in these Kebeles. The objective living conditions in these Kebeles are relatively good mainly due to the fact that these Kebeles are less crowded and have respondents with high economic condition compared to other Kebeles. The subjective QoL of the four Kebeles is low compared to the objective QoL probably due to the fact that the respondents are dissatisfied with some of the domains of life. For instance, the respondents in these four Kebeles, expressed dissatisfaction with housing, income and sanitation.

Both subjective and objective living conditions are bad in Kebele 13/14, K15/16 and $\mathrm{K} 20 / 21$. We can say that there is deprivation in these Kebeles. The opposite is the case where both subjective and objective living conditions are good, like in Kebeles 02/03, K04 and K17/18. We can then say there is well-being in those Kebeles. 


\section{Conclusion}

In this study, the subjective QoL is measured and its spatial distribution is evaluated in Kirkos sub-city of Addis Ababa while the objective QoL is estimated from objective attributes that are collected from field survey. At the sub-city level, the mean score of response of the respondents indicate that the respondents are dissatisfied with the quality of their life. However, there is large variation between the QoL of the respondents in the subcity. For instance, about $4 \%$ of the respondents in the sub-city are 'completely satisfied' and $15 \%$ are 'completely dissatisfied'. The remaining $81 \%$ of the respondents expressed a satisfaction level that ranges between the two extremes.

At smaller scale than the sub-city, i.e., at Kebele level, respondents of all Kebeles expressed dissatisfaction. However, there is a large variation at Kebele level within the expressed satisfaction of respondents. The results indicate that aggregation at larger scale, i.e., the sub-city level, can average out the variability of QoL that exists at small scales, i.e., at Kebele level in this study.

The variability in the subjective QoL in the sub-city is evaluated using coefficient of variation $(\mathrm{CV})$. The result indicated that the variability of QoL in each Kebele decreases somehow exponentially as the QoL in the Kebele increases. Such result suggests that Kebeles with high QoL are perceived relatively homogeneous in terms of QoL while Kebeles with low QoL are perceived relatively heterogeneous.

The dimensions of the objective QoL in Kirkos are crowdedness, socio-economic status, safety and proximity, housing and demography. Using these dimensions of objective QoL, an index of objective QoL is developed. The combined effect of subjective and objective QoL in the sub-city is studied using the subjective QoL score and the index that is developed for the objective QoL. The combined effect of the subjective and the objective QoL indicated a state of dissonance, adaptation, deprivation or wellbeing in each Kebele. Well-being and deprivation indicate the subjective and the objective perspectives measured the same level of QoL. However, dissonance and adaptation indicate the subjective and the objective perspectives do not necessary measure the same level of QoL. The result in this study also indicates the need to study the combined effect of both subjective and objective QoL. Relative to the subjective perspective, the objective perspective lacks validity since most of the formulation of the index is determined by the researchers' judgment, standards and norms or existing formulations that may not accurately reflect residents' satisfaction.

In general, the findings of this study indicate that large scale study can hide the variability of QoL at small scales. The findings also reveal the importance of studying both subjective and objective QoL instead of any one of these separately.

It is expected that the results and finding of this study will be useful in designing future urban QoL studies in the region. Studying QoL at the city level, i.e., Addis Ababa, was not the focus in this study and such can be considered in future studies.

The outcomes of these studies may help local planners in improving and having a better understanding of the quality of life conditions of the population. Consequently they can better prioritize the problems that the community face as well as the most deprived areas.

Open Access This article is distributed under the terms of the Creative Commons Attribution Noncommercial License which permits any noncommercial use, distribution, and reproduction in any medium, provided the original author(s) and source are credited. 


\section{References}

Apparicio, P., Seguin, A.-M., \& Daniel, N. (2008). The quality of urban environment around public housing buildings in Montreal: An objective approach based on GIS and multivariate statistical analysis. Social Indicators Research, 86, 355-380.

Bonaiuto, M., Fornara, F., \& Bonnes, M. (2003). Indexes of perceived residential environment quality and neighbourhood attachment in urban environments: A confirmation study on the city of Rome. Landscape and Urban Planning, 65(1-2), 41-52.

Bramston, P., Pretty, G., \& Chipuer, H. (2002). Unravelling subjective quality of life: An investigation of individual and community determinants. Social Indicators Research, 59, 261-274.

Brereton, F., Clinch, J. P., \& Ferreira, S. (2008). Happiness, geography and the environment. Ecological Economics, 65(2), 386-396.

Central statistical agency of Ethiopia. (2007). Retrieved January 15 2009, from http://www.csa.gov.et.

Craglia, M., Leontidou, L., Nuvolati, G., \& Schweikart, J. (2004). Towards the development of quality of life indicators in the 'digital' city. Environment and Planning B-Planning and Design, 31(1), 51-64.

Das, D. (2008). Urban quality of life: A case study of Guwahati. Social Indicators Research, 88, $297-310$.

Foo, T. S. (2000). Subjective assessment of urban quality of life in Singapore (1997-1998). Habitat International, 24(1), 31-49.

Higgs, N. (2007). Measuring and understanding the well-being of South-Africans: Everyday quality of life in South-Africa. Social Indicators Research, 81, 331-356.

Ibrahim, M., \& Chung, W. (2003). Quality of life of residents living near industrial estates in Singapore. Social Indicators Research, 61, 203-225.

Lee, Y.-J. (2008). Subjective quality of life measurement in Taipei. Building and Environment, 43(7), 12051215.

Li, G., \& Weng, Q. (2007). Measuring the quality of life in city of Indianapolis by integration of remote sensing and census data. International Journal of Remote Sensing, 28(2), 249-267.

Marans, R. W. (2003). Understanding environmental quality through quality of life studies: The 2001 DAS and its use of subjective and objective indicators. Landscape and Urban Planning, 65(1-2), 73-83.

McCrea, R., Shyy, T.-K., \& Stimson, R. (2006). What is the strength of the link between objective and subjective indicators of urban quality of life? Applied Research in Quality of Life, 1(1), 79-96.

Mccrea, R., Stimos, R., \& Western, J. (2005). Testing a moderated model of satisfaction with urban living using data for Brisbane-south east Queensland, Australia. Social Indicator Research, 72, 121-152.

Møller, V. (2007). Quality of life in South Africa: The first ten years of democracy. Social Indicators Research, 81(2), 181-201.

Moro, M., Brereton, F., Ferreira, S., \& Clinch, J. P. (2008). Ranking quality of life using subjective wellbeing data. Ecological Economics, 65(3), 448-460.

Richards, R., O'leary, B., \& Mutsonziwa, K. (2007). Measuring quality of life in informal settlements in South Africa. Social Indicator Research, 81, 375-388.

Rogerson, R., Findlay, A., \& Morris, A. (1989). Indicators of quality of life: Some methodological issues. Environment and Planning A, 21(12), 1655-1666.

Tesfazghi, E. S. (2009). Urban quality of life and its spatial distribution in Addis Ababa: Kirkos sub-city. Enschede: ITC.

Turksever, A. N., \& Atalik, G. (2001). Possibilities and limitations for the measurement of the quality of life in urban areas. Social Indicators Research, 53, 163-187.

Van Kamp, I., Leidelmeijer, K., Marsman, G., \& de Hollander, A. (2003). Urban environmental quality and human well-being: Towards a conceptual framework and demarcation of concepts; a literature study. Landscape and Urban Planning, 65(1-2), 5-18.

Wong, C. (2001). The relationship between quality of life and local economic development: An empirical study of local authority areas in England. Cities, 18, 25-32.

Zapf, W. (1984). Individuelle Wohlfahrt: Lebensbedingungen und wahrgenommene Lebensqualität [Individual welfare: Living conditions and noticed quality of life]. In W. Glatzer \& W. Zapaf (Eds.), Lebensqualität in der Bundesrepublik. Objektive Lebensbedingungen und subjektives Wohlempfinden (pp. 13-26). Campus: Frankfurt am Main.

Zebardast, E. (2009). The housing domain of quality of life and life satisfaction in the spontaneous settlements on the Tehran metropolitan fringe. Social Indicators Research, 90, 307-324. 